\title{
Análisis de 5 universidades colombianas con mayor porcentaje de investigaciones publicadas en revistas de primer cuartil según el SIR Iber 2014
}

\section{Analysis of five Colombian Universities with more Published Researcher in Journals of the First Quartile According to the SIR Iber 2014}

\author{
Rosa Elena Gómez Hurtado * \\ Fundación Universitaria UNINPAHU. \\ Bogotá, Colombia \\ Alexander Gerena Herrera ** \\ Fundación Universitaria UNINPAHU \\ Bogotá, Colombia
}

\section{Resumen}

Se realizó un estudio en cinco universidades con mayor porcentaje de publicaciones en revistas de primer cuartil, según el ranking internacional SCImago Institutions Rankings Iberoamerica 2014 (SIR Iber 2014). Los registros procedentes del SIR Iber 2014 fueron exportados a una base de datos y mediante una hoja de cálculo en Excel se elaboraron tablas y gráficos que permitieron hacer recuentos estadísticos, análisis de frecuencias y análisis de cluster. Se hizo una revisión del tamaño de la producción, el impacto científico, la especialización temática y la colaboración entre las universidades en los ámbitos nacional e internacional.

El estudio se realizó a partir de la revisión de los resultados obtenidos en el SIR Iber 2014, complementados con los datos obtenidos en las bases de datos Scopus y WoS, respecto a las primeras cinco universidades colombianas que, en ese año, publicaron más trabajos en revistas de primer

\section{bibliotecas}


cuartil (Q1). Los principales resultados muestran las universidades con mejor posición en el ranking SIR Iber 2014, de acuerdo con los criterios bibliométricos analizados: colaboración internacional, impacto, publicaciones de alta calidad, excelencia y liderazgo científico.

Palabras clave: bibliometría, informetría, cienciometría, rankings universitarios, revistas científicas.

\begin{abstract}
A study of five universities with the highest percentage of publications in first quartile journals according to the international ranking SCImago Institutions Rankings Iberoamerica 2014 (SIR Iber 2014) was carried out. The records from the SIR Iber 2014 were exported to a database and by means of a spreadsheet in Excel tables and graphs were elaborated that allowed to make statistical counts, frequency and cluster analysis; among others. A review of the size of production, scientific impact, thematic specialization and collaboration between universities at the national and international contexts was made.
\end{abstract}

The study was carried out based on the review of the results obtained in the SIR Iber 2014, complemented with the data obtained from the Scopus and WOS databases related to the first five colombian universities published more papers in first-year journals Quartile (Q1). The main results show the universities with the best rank in the SIR Iber 2014 ranking according to the bibliometric criteria analyzed: international collaboration

Keywords: bibliometrics, informetrics, scientometrics, university rankings, scientific publications. 


\section{Introducción}

Los rankings universitarios surgen por tres razones: responder a la necesidad de orientar a los estudiantes en la elección de la institución donde cursan estudios; informar a los gestores de la universidad sobre sus fortalezas y debilidades en todos los ámbitos de su actividad e impulsar a los responsables de la política educativa (internacional, nacional o regional) para la toma de decisiones, bien sea en la planificación estratégica de instituciones o titulaciones o en la financiación de las propias universidades (López, 2012).

No obstante, diversos autores coinciden en afirmar que los rankings universitarios sirven para levantar el ánimo de las universidades, en vista de que permiten a algunas instituciones ganar mayor reputación que otras; afectan diferentes ámbitos de la toma de decisiones en las universidades; condicionan la planeación estratégica al modificar los objetivos y prioridades; inciden en la financiación en cuanto determinan la captación y recaudación de fondos, al tiempo que también determinan las políticas y colaboración con otras instituciones académicas en diversos proyectos; determinan la política web de la universidad; orientan la productividad investigadora; refuerzan los estímulos a la publicación en medios de referencia internacional y tienen un alto impacto en los gobiernos nacionales para actuar como examinadores críticos de los sistemas universitarios (López, 2012).

Inicialmente, los rankings universitarios se crearon para medir la efectividad de las universidades y su trabajo consistía en considerar los avances internos. Hoy, los líderes de estas instituciones, están valorando su utilización porque los gobiernos y los estudiosos de las políticas públicas suponen que la participación de la Universidad en estos sistemas constituye una forma de evaluar su dirección, de tal forma que se tomen acciones que las lleven a posicionarse de mejor manera en la estructura del ranking (Shin, 2011).

Entre los rankings más conocidos se encuentran:

- Shanghai (ARWU). Elaborado por la Universidad Jiao Tong de Shanghai que ordena las 500 mejores universidades del mundo en función de criterios de calidad como el 
nivel de los estudiantes, el profesorado y los centros, la actividad investigadora y las publicaciones.

- The Times Higher Education (Reino Unido). Analiza 5.000 universidades de todo el mundo, basado en indicadores como la presencia de premios nobel entre los profesores o los egresados de las instituciones o la prioridad que se les da a los resultados de investigación en las publicaciones periódicas de más alta visibilidad e impacto.

- QS World University Ranking. Es una clasificación mundial de universidades elaborada y publicada en la web desde el 2004 por el grupo Quacquarelli Symonds que estratifica las universidades según criterios que han tenido amplio impacto. En general este ranking tiene indicadores como la percepción de académicos, egresados y estudiantes acerca de las universidades, mediante la aplicación de encuestas.

- La universidad de Granada publica el SClmago Institution Ranking (SIR) en su versión para América Latina (SIR Iber 2014). Este ranking escalafona las universidades a partir de ocho criterios:

a) El Output (O) organiza las instituciones según el número de investigaciones indexadas en Scopus.

b) La colaboración internacional $(\% \mid C)$ presenta el porcentaje de las publicaciones producidas en colaboración con instituciones de otro país.

c) El impacto normalizado (NI) representa la relación del factor de impacto de cada institución con el conjunto promedio mundial.

d) Las publicaciones de alta calidad (\%Q1) representan el porcentaje de las investigaciones que se publicaron en revistas de primer cuartil.

e) El índice de especialización (Spec) indica el grado de concentración temática o dispersión de la producción científica que utiliza la fórmula del índice Gini, que no se pudo calcular debido a que los datos no son suficientes para hacerlo (Moed, et al., 2011; López, Moya, Moed, 2011; Arencibia et al., 2012).

f) La ratio de excelencia (\%exc) mide la cantidad de producción científica de alta calidad de las instituciones de investigación (SCImago Lab, 2011). 
g) El liderazgo científico (\%Lead) muestra el porcentaje de artículos publicados por autores con filiación institucional.

h) La excelencia con liderazgo (\%Ewl) que indica el porcentaje de documentos publicados en revistas de primer cuartil en que la institución es el principal contribuidor (Molina-Molina y De Moya, 2013).

- El ranking webometrics desarrollado por el Laboratorio de Cibermetría (España) está basado en indicadores web que miden qué tan visible es la universidad en la web y qué tan accesible es la información sobre sus actividades de investigación, entre otros aspectos. Sus indicadores son tamaño, que se mide por el número de páginas recuperadas desde los motores de búsqueda Google, Yahoo y Bing. Visibilidad o número total de enlaces externos únicos recibidos por un sitio de acuerdo con Yahoo Site Explorer. El volumen de los formatos de archivo disponibles en los formatos .pdf, .ps, .doc y .ppt, obtenidos a través de Google, Yahoo y Bing y, el último, se obtiene del número de artículos publicados en Google Scholar y de la producción mundial obtenida de Scimago SIR.

- El ranking U-Sapiens publicado por el Sapiens Research Group de Colombia (http://www.sapiensresearch.org/usapiens/2015-1/metodologia.html) es un escalafón que clasifica las universidades colombianas según los siguientes indicadores de investigación: (1) revistas indexadas en Publindex (en el cual se publican los resultados de investigación), (2) maestrías o doctorados y (3) grupos de investigación, según se muestra en la siguiente Figura 1.

Figura 1

Indicadores del ranking U-Sapiens

1. Revistas indexadas en Publindex

\begin{tabular}{|c|c|c|c|c|}
\hline Publicaciones A1 & Publicaciones A2 & Publicaciones B & Publicaciones C \\
\hline 1 & 0,75 & 0,50 & 0,25 \\
\hline \multicolumn{5}{|c|}{ 2. Maestrías y doctorados } \\
\hline \multicolumn{5}{|c|}{ Maestrías } \\
\hline \multicolumn{5}{|c|}{0,4} \\
\hline \multicolumn{5}{|c|}{ 3. Grupos de investigación } \\
\hline Grupos A1 & Grupos A & Grupos B & Grupos C & Grupos D \\
\hline 1 & 0,8 & 0,6 & 0,4 & 0,2 \\
\hline
\end{tabular}

Fuente: Sapiens Research Group (2014) 
En este ranking, las revistas indexadas en Publindex son clasificadas de acuerdo con las categorías C, B, A2 y A1 de mayor a menor; se tienen en cuenta los programas de maestrías y doctorados activos, aprobados que pueden ser ofertados y recibir estudiantes según el Ministerio de Educación Nacional. Finalmente, los grupos de investigación son categorizados como D, C, B, A y A1, de menor a mayor. La metodología se aplica de la siguiente forma:

1. A cada una de las subdivisiones de los indicadores se les asigna un peso proporcional entre 0 y 1 , según importancia y equitatividad, para ser multiplicado por el número total aplicado a cada sub-división (P.e: $C * 0,25$ ). El total que se aplica a cada sub-división por grupo de indicadores se entiende de la siguiente manera:

a. Número de revistas indexadas en Publindex. Relación con investigación: artículos publicados derivados de investigaciones nacionales e internacionales.

b. Número de maestrías-doctorados aprobados que pueden ser ofertados y recibir estudiantes. Relación con investigación: formación de investigadores y científicos.

c. Número relativo de grupos de investigación categorizados por Colciencias. Relación con investigación: formulación y desarrollo de proyectos y actividades de investigación científico-tecnológicas.

2. Se suman los resultados de la operación anterior por cada una de las subdivisiones de cada indicador.

3. A estos nuevos resultados se les da un peso alfa, beta y gama (que corresponde, de manera inversamente proporcional, a la participación de la sumatoria total de cada uno de los indicadores sobre el resultado total de adicionar las sumatorias de los tres indicadores).

4. Finalmente, se suman los resultados de cada indicador, con el fin de obtener un puntaje para cada institución de educación superior. (Scimago Research Group, 2014)

Desde esta perspectiva y a partir la cienciometría, en la construcción de los más diversos rankings de universidades que hacen de su actividad un producto de mercado y un medio para promoverla como servicio especializado, en cuanto a la economía del conocimiento aparecen muy pocas universidades de América latina y en particular de Colombia, lo que lleva a preguntarse por la viabilidad y pertinencia de la educación superior (Plata, 2013). 
Si bien es cierto que la producción científica en Colombia es cada vez mayor en Scopus y que se están mejorando las prácticas de comunicación científica, se debe acompañar estos resultados con un mayor énfasis en los indicadores de calidad y ajustes a las políticas relacionadas con la producción científica, con miras a lograr una mayor visibilidad internacional y un sistema de incentivos a investigadores e instituciones de educación superior más eficiente (Molina-Molina y De Moya, 2013).

Este artículo analiza la clasificación de las cinco universidades colombianas con mayor porcentaje de publicaciones en revistas de primer cuartil en el ranking SIR Iber 2014, teniendo en cuenta los indicadores del SCImago Institution Ranking (SIR); el tamaño de la producción, impacto científico, especialización temática y colaboración institucional, sin desconocer que debe descartarse el uso de la evaluación científica a partir de indicadores bibliométricos aislados o de carácter absoluto (González de Dios, Moya, Mateos, 1997).

\section{Marco Referencial}

Gracias a la masificación de la educación superior y al incremento en la idoneidad e internacionalización de ésta, las Instituciones de Educación Superior (IES) se preocupan cada vez más por estudiar los mecanismos del mercado para lograr mayores niveles de competitividad, lo cual ha influido en el nivel de popularidad que han alcanzado los rankings como herramientas de posicionamiento. El lugar que una institución de educación superior ocupa en el ranking le facilita no solo la definición de políticas educativas, sino también el diseño o rediseño de estrategias de posicionamiento con ventajas competitivas.

En este contexto, los rankings se han convertido en una alternativa para evaluar las Instituciones de Educación Superior (IES) o sus programas académicos, a partir del punto de vista de su eficiencia y con la pretensión de establecer algunos parámetros acerca de la calidad de la educación superior (Shin, 2011). Se podría decir que los rankings universitarios se han creado para medir, ante todo, un tipo de institución caracterizada por ser intensiva en investigación, con amplias posibilidades de acceso a recursos de financiación y que publique sus resultados en revistas científicas de alta visibilidad e impacto. 
Varios autores, entre ellos Sadlak (2004) y Nian (2007), han manifestado sus inquietudes con respecto a la construcción de los rankings, relacionadas con aspectos como la validez de los indicadores utilizados, la forma en cómo se captura la información, las ponderaciones empleadas para llegar a un solo valor asignado a cada institución y la tendencia a resaltar diferencias que son realmente mínimas cuando se ordenan las instituciones de forma ascendente en función del valor único obtenido, sin preguntarse en ningún momento qué grado de diferenciación es deseable o aceptable entre ellas (Pérez, 2016).

Lo anterior lleva a considerar erróneo pensar que ante el amplio espectro de perfiles y propósitos institucionales, todas las instituciones de educación superior se pueden ver reflejadas en dichos rankings; evidencia de ello es que los rankings internacionales de mayor reputación logran capturar información apenas de un subconjunto bastante reducido del total de IES existentes (Pérez, 2016).

\section{a. Los cuartiles para clasificar las revistas científicas}

La producción científica de una institución de educación superior es la producción de la institución medida por el número de publicaciones en revistas científicas, por la cual se puede tener una idea general de su tamaño. Con más de tres siglos de antigüedad, las publicaciones científicas formales continúan considerándose como los eslabones básicos en el proceso de transferencia y difusión de la ciencia y un instrumento privilegiado para la comunicación entre los investigadores (López y Cordero, 2015).

Junto a la función social de difundir la ciencia, las revistas cumplen otros importantes roles: son el medio más rápido para conocer los últimos avances sobre un campo específico del conocimiento, constituyen el mecanismo propicio para evaluar la actividad científica, permiten controlar y certificar la calidad de los resultados de investigación y si se garantiza su accesibilidad se transforman en un archivo público del conocimiento, según el Centro de Información y Documentación Científica (CINDOC). Teniendo en cuenta el tipo de contribuciones, las revistas pueden ser de cuatro tipos: 
- De información, en las cuales se divulgan programas (científicos, técnicos, educativos, etc.), reuniones de interés científico o artículos breves que informan sobre personas destacadas en algún aspecto de la ciencia.

- Primarias que publican artículos científicos originales.

- Secundarias que recogen el contenido de las revistas primarias.

- Terciarias en las cuales se publican informes resumidos de programas de investigación.

Con el propósito de evaluar su calidad, las revistas científicas se han clasificado en cuartiles, que son un escalafón definido como "la unidad más utilizada para la medida de posición de una revista". Se utiliza separando los grupos de revistas de una determinada especialidad, ordenados de mayor a menor visibilidad (factor de impacto). Si un listado de revistas ordenadas de mayor a menor factor de impacto se divide en 4 grupos iguales, cada una de estas partes constituye un cuartil. Aquellas que contengan mayor factor de impacto estarán en el primer cuartil y el más bajo será el cuarto (Sobrido, 2011, p.2).

Así, el hecho de que una revista haga parte del primer cuartil de su campo de investigación es un indicador de excelencia y alta calidad; para las instituciones publicar en estas revistas representa un grado de excelencia en su investigación, lo cual les permite mejorar su visibilidad y posicionamiento en los rankings nacionales e internacionales. Una revista en el cuarto cuartil (Q4) puede indicar que sus contenidos son una fuente de diálogo menos denso por parte de los investigadores de una temática determinada $y$, consecuentemente, en la medida en que una revista sube de cuartil muestra que la comunidad la usa en forma más significativa, sugiriendo además que es una fuente de diálogo disciplinar central. De esta forma, es claro que una revista en cuartil uno (Q1) puede indicar que se encuentra en la corriente principal del diálogo académico e investigativo. 


\section{Materiales y Métodos}

El estudio se realizó a partir de la revisión de los resultados obtenidos en el SIR Iber 2014 complementados con los datos obtenidos de las bases de datos Scopus y WOS con respecto a las primeras cinco universidades colombianas que en ese año publicaron más trabajos en revistas de primer cuartil (Q1). Los registros procedentes del SIR lber 2014 fueron exportados a una base de datos y mediante una hoja de cálculo en Excel se elaboraron tablas y gráficos que permitieron hacer recuentos estadísticos, análisis de frecuencias y análisis de cluster; los cuales se discriminaron con base en los siguientes variables o indicadores:

- Índice de autores más productivos: es la producción de la institución medida en número de publicaciones en revistas científicas de cuartil 1.

- Porcentaje de publicaciones en revistas del primer cuartil SJR (Q1): indica el porcentaje de las publicaciones que una universidad ha publicado en revistas científicas incluidas en el primer cuartil, ordenadas por el indicado del Scimago Journal Ranking (SJR).

- Producción por áreas del conocimiento: es la producción de una institución, medida por las áreas del conocimiento en que se han producido los documentos.

- Colaboración interinstitucional: es la ratio de publicaciones científicas de una institución que han sido elaboradas conjuntamente con otras instituciones.

- Índice de colaboración internacional: es el SJR que mide la influencia o prestigio científico de las revistas mediante el análisis de la cantidad y la procedencia de las citas que recibe una revista científica.

Es preciso mencionar que para la ponderación del SIR Iber 2014, Scimago utilizó los datos de la producción científica relativa al periodo 2008-2012. Respecto a la investigación se utilizaron los datos de la producción científica de las Instituciones de Educación Superior objeto de estudio correspondiente al año 2014. 


\section{Resultados}

\section{a. Análisis de las primeras cinco universidades colombianas con mayor porcentaje de publicaciones en revistas de primer cuartil \%Q1}

El SCImago Institutions Rankings (SIR) clasifica las IES teniendo en cuenta diversos indicadores de la actividad investigadora para medir los resultados de producción científica, colaboración internacional, calidad científica promedio y porcentaje de publicaciones en revistas del primer cuartil en SCImago Journal \& Country Rank (SJR), entre otros, por lo cual los resultados cambian según el criterio de análisis que se esté utilizando. El SJR incluye un indicador propio que calcula el valor de las revistas en función del origen de las citas recibidas, es decir, que valdrán más las citas recibidas cuanto mejor sea la revista (Pinski y Narin, 1976).

\section{Cuadro 1}

\section{Primeras 40 universidades colombianas clasificadas según el SIR Iber 2014}

O Output - \%IC Colaboración internacional - NI. Impacto normalizado - \%Q1 Publicaciones de alta calidad - Esp Índice de especialización - \% Exe Índice de excelencia - \% lid Liderazgo científico - \% E/L Excelencia y liderazgo.

\begin{tabular}{|c|c|c|c|c|c|c|c|c|c|}
\hline $\mathbf{N}^{\circ}$ & Institución & 0 & $\%$ IC & NI & $\%$ Q1 & Esp & $\begin{array}{c}\% \\
\text { Exe }\end{array}$ & $\begin{array}{c}\% \\
\text { Lid }\end{array}$ & $\begin{array}{c}\% \% \\
E / L\end{array}$ \\
\hline 1 & Univ. Nacional de Colombia & 6077 & 38,16 & 0,57 & 21,24 & 0,16 & 4,67 & 64,65 & 1,96 \\
\hline 2 & Univ. de Antioquia & 3187 & 49,67 & 0,69 & 27,46 & 0,19 & 6,67 & 60,37 & 2,21 \\
\hline 3 & Univ. de los Andes, Colombia & 2423 & 56,62 & 1,67 & 39,66 & 0,1 & 16,12 & 51,22 & 2,2 \\
\hline 4 & Univ. del Valle & 1676 & 48,03 & 0,64 & 22,20 & 0 & 5,24 & 56,21 & 2,03 \\
\hline 5 & Pontificia Univ. Javeriana & 1425 & 43,93 & 0,62 & 23,02 & 0,04 & 5,41 & 58,53 & 0,7 \\
\hline 6 & Univ. Industrial de Santander & 1145 & 45,24 & 0,71 & 23,32 & 0,03 & 7,16 & 58,95 & 3,14 \\
\hline 7 & Univ. del Rosario & 711 & 38,26 & 0,77 & 30,24 & 0,38 & 8,61 & 51,76 & 1,87 \\
\hline 8 & Univ. Pontificia Bolivariana & 539 & 44,53 & 0,68 & 20,59 & 0,19 & 4,59 & 51,76 & 0,46 \\
\hline 9 & Univ. del Norte & 449 & 50,78 & 0,89 & 21,60 & 0,26 & 7,55 & 55,01 & 1,35 \\
\hline 10 & Univ. de Cartagena & 377 & 29,18 & 0,47 & 17,77 & 0,39 & 4,3 & 68,44 & 1,61 \\
\hline 11 & Univ. Tecnológica de Pereira & 374 & 48,66 & 0,84 & 20,59 & 0,36 & 8,49 & 59,36 & 2,58 \\
\hline 12 & Univ. Distrital Francisco José de Caldas & 366 & 28,14 & 0,43 & 7,10 & 0,71 & 2,79 & 72,13 & 0 \\
\hline 13 & Univ. del Cauca & 350 & 58,86 & 0,79 & 15,71 & 0,38 & 7,17 & 52 & 3,23 \\
\hline 14 & Univ. EAFIT & 338 & 40,83 & 0,4 & 20,41 & 0,48 & 2,04 & 63,31 & 1,22 \\
\hline 15 & Univ. de Caldas & 335 & 40,9 & 0,64 & 14,63 & 0,51 & 7,67 & 59,4 & 3,51 \\
\hline
\end{tabular}




\begin{tabular}{|c|c|c|c|c|c|c|c|c|c|}
\hline 16 & Univ. de La Sabana & 276 & 35,14 & 0,47 & 19,57 & 0,36 & 3,82 & 59,78 & 0,76 \\
\hline 17 & Univ. de Córdoba & 267 & 39,7 & 0,28 & 12,73 & 0,57 & 1,56 & 56,93 & 0,39 \\
\hline 18 & Univ. Antonio Nariño & 260 & 83,08 & 6,04 & 62,31 & 0,81 & 40,16 & 13,85 & 0,8 \\
\hline 19 & Univ. del Quindío & 252 & 50,79 & 0,7 & 16,27 & 0,15 & 6,76 & 57,14 & 2,7 \\
\hline 20 & Univ. CES & 244 & 29,92 & 0,47 & 16,39 & 0,68 & 2,55 & 52,46 & 0,43 \\
\hline 21 & Univ. Pedagóg. y Tecnológica de Colombia & 228 & 42,98 & 0,34 & 12,28 & 0,49 & 2,42 & 60,96 & 0,97 \\
\hline 22 & Univ. Militar Nueva Granada & 213 & 35,21 & 0,55 & 14,55 & 0,53 & 4 & 54,46 & 1,14 \\
\hline 23 & Univ. El Bosque & 190 & 52,63 & 1,22 & 38,95 & 0,67 & 14,36 & 32,63 & 2,66 \\
\hline 24 & Univ. del Tolima & 188 & 60,64 & 1,08 & 28,19 & 0,28 & 11,35 & 35,11 & 3,78 \\
\hline 25 & Univ. Autónoma de Occidente & 176 & 50 & 0,88 & 17,61 & 0,65 & 9,49 & 51,14 & 4,38 \\
\hline 26 & Univ. del Magdalena & 163 & 39,88 & 0,69 & 15,34 & 0,69 & 5,84 & 53,37 & 2,6 \\
\hline 27 & Univ. de Nariño & 157 & 46,5 & 0,39 & 21,66 & 0,53 & 1,36 & 52,23 & 0,68 \\
\hline 28 & Univ. de Pamplona & 152 & 63,16 & 0,66 & 23,68 & 0,27 & 4,41 & 53,29 & 0,74 \\
\hline 29 & Univ. de Bogotá Jorge Tadeo Lozano & 145 & 53,79 & 0,95 & 28,97 & 0,62 & 7,41 & 55,17 & 2,22 \\
\hline 30 & Univ. ICESI & 136 & 31,62 & 0,22 & 9,56 & 0,61 & 0,96 & 57,35 & $v$ \\
\hline 31 & Univ. de La Salle Colombia & 125 & 36 & 0,36 & 16,80 & 0,69 & 1,96 & 44,8 & $v$ \\
\hline 32 & Univ. Santo Tomas, Colombia & 120 & 34,17 & 0,24 & 9,17 & 0,7 & 1,06 & 50 & 0 \\
\hline 33 & Univ. de San Buenaventura & 108 & 26,85 & 0,23 & 9,26 & 0,74 & 3,16 & 63,89 & 0 \\
\hline 34 & Instituto Tecnológico Metropolitano & 93 & 32,26 & 0,51 & 15,05 & 0,82 & 4,55 & 51,61 & 2,27 \\
\hline 35 & Univ. Autónoma de Bucaramanga & 84 & 40,48 & 0,61 & 13,10 & 0,65 & 7,14 & 47,62 & 0 \\
\hline 36 & Univ. del Atlántico & 83 & 45,78 & 0,3 & 13,25 & 0,53 & 2,56 & 33,73 & 0 \\
\hline 36 & Univ. Libre & 83 & 19,28 & 0,3 & 7,23 & 0,68 & 1,52 & 56,63 & 0 \\
\hline 37 & Univ. de Sucre & 81 & 30,86 & 0,19 & 6,17 & 0,77 & 0 & 71,6 & 0 \\
\hline 38 & Univ. Surcolombiana & 79 & 43,04 & 0,61 & 20,25 & 0,77 & 6,94 & 51,9 & 0 \\
\hline 39 & Univ. de Los Llanos & 76 & 35,53 & 0,23 & 7,89 & 0,89 & 0 & 69,74 & $u$ \\
\hline 40 & Univ. Externado de Colombia & 75 & 26,67 & 0,18 & 8,00 & 0,92 & 1,47 & 76 & 1,47 \\
\hline
\end{tabular}

Fuente: diseño propio basado en el SIR Iber 2014.

Se observa que las posiciones que ocupan las IES colombianas en esta lista varían si el análisis se realiza teniendo en cuenta el criterio Output $(\mathrm{O})$ referente al número de investigaciones que las universidades tienen indexadas en Scopus. Según este criterio, las primeras posiciones del escalafón son ocupadas por universidades con tradición investigativa en Colombia como la Universidad Nacional de Colombia, Universidad de Antioquia, Universidad de los Andes, Universidad del Valle y Universidad Javeriana. No obstante, en este ranking la Universidad Antonio Nariño aparece ubicada en la posición No. 18 del escalafón general. 
En contraste con estos resultados, al ordenar el listado de universidades de acuerdo con el criterio "porcentaje de las investigaciones que se publicaron en revistas de primer cuartil" (\%Q1), la Universidad Antonio Nariño aparece en primer lugar; por encima de las universidades de los Andes, El bosque, Rosario y Jorge Tadeo Lozano que tradicionalmente ocupaban los primeros lugares (Cuadro 2).

El Cuadro 3 evidencia la variación en la posición de las universidades objeto de estudio según el porcentaje de investigaciones que publicaron en revistas de primer cuartil (\%Q1), versus el número de investigaciones indexadas en Scopus (O) del Sir lber 2014.

\section{Cuadro 2}

\section{Principales universidades que publican en revistas de primer cuartil (\% Q1)}

O Output - \%IC Colaboración internacional - NI. Impacto normalizado. - \%Q1 Publicaciones de alta calidad. - Esp Índice de especialización. - \% Exe Î́ndice de excelencia. - \% lid Liderazgo científico. $\%$ E/L Excelencia y liderazgo.

\begin{tabular}{|c|c|c|c|c|c|c|c|c|c|}
\hline No. & Institución & 0 & $\%$ IC & NI & $\%$ Q1 & Esp & $\begin{array}{l}\% \\
\text { Exe }\end{array}$ & $\begin{array}{l}\% \\
\text { Lid }\end{array}$ & $\begin{array}{l}\% \% \\
E / L\end{array}$ \\
\hline 1 & Univ. Antonio Nariño & 260 & 83,08 & 6,04 & 62,31 & 0,81 & 40,16 & 13,85 & 0,8 \\
\hline 2 & $\begin{array}{l}\text { Univ. de los Andes } \\
\text { Colombia }\end{array}$ & 2423 & 56,62 & 1,67 & 39,66 & 0,1 & 16,12 & 51,22 & 2,2 \\
\hline 3 & Univ. El Bosque & 190 & 52,63 & 1,22 & 38,95 & 0,67 & 14,36 & 32,63 & 2,66 \\
\hline 4 & Univ. del Rosario & 711 & 38,26 & 0,77 & 30,24 & 0,38 & 8,61 & 51,76 & 1,87 \\
\hline 5 & $\begin{array}{l}\text { Univ. de Bogotá Jorge } \\
\text { Tadeo Lozano }\end{array}$ & 145 & 53,79 & 0,95 & 28,97 & 0,62 & 7,41 & 55,17 & 2,22 \\
\hline
\end{tabular}

Fuente: diseño propio basado en el SIR Iber 2014.

\section{Cuadro 3}

IES con mayor \% de publicaciones en revistas de primer cuartil (\%Q1) e investigaciones indexadas en Scopus ( 0 )

\begin{tabular}{lcc}
\hline \multicolumn{1}{c}{ Institución } & $\begin{array}{c}\text { Posición } \\
\text { según (\%Q1) }\end{array}$ & $\begin{array}{c}\text { Posición } \\
\text { según (0) }\end{array}$ \\
\hline Universidad Antonio Nariño & 1 & 18 \\
Universidad de los Andes & 2 & 3 \\
Universidad El Bosque & 3 & 23 \\
Universidad del Rosario & 4 & 7 \\
Universidad de Bogotá Jorge Tadeo Lozano & 5 & 23 \\
\hline
\end{tabular}

Fuente: Diseño propio basado en datos tomados SIR Iber 2014. 
Es prudente advertir que las universidades que lideran el ranking por tener mayor cantidad de investigaciones publicadas en revistas indexadas en Scopus (Gráfico 1), no necesariamente publican sus trabajos en revistas de primer cuartil e inclusive puede que tengan muchos más trabajos publicados en revistas que no están indizadas en Scopus o que son de acceso abierto.

\section{Gráfico 1}

Cantidad de documentos indexados por las universidades vs porcentaje de publicaciones en revistas de primer cuartil

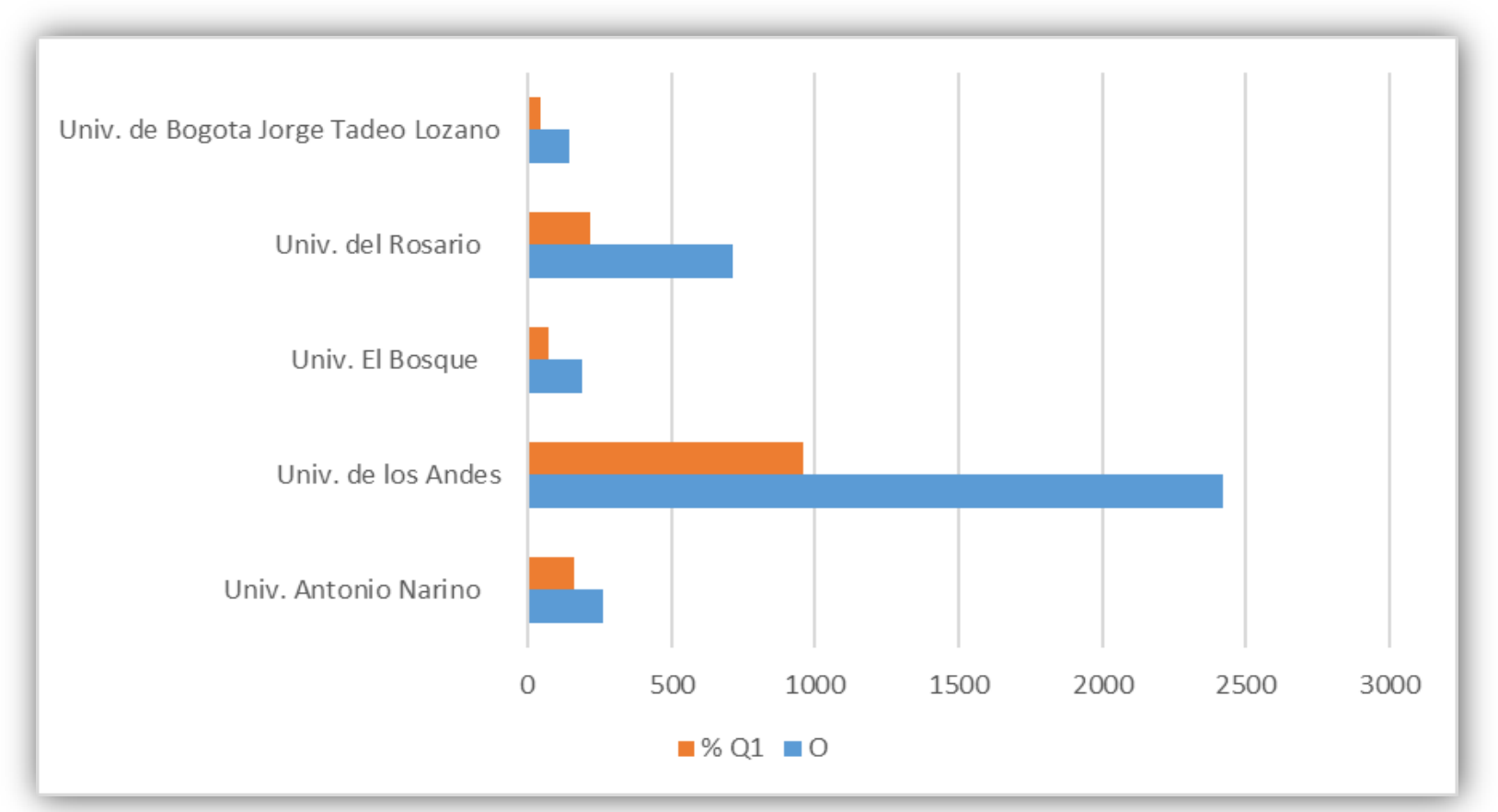

Fuente: Diseño propio basado en datos tomados de SIR Iber 2014.

En este gráfico se destaca la Universidad de los Andes con mayor número de documentos indexados en Scopus (2.423). Sin embargo, es necesario precisar que del total de documentos publicados por la Universidad de Los Andes, solo el $39.66 \%$ corresponde a revistas de primer cuartil, mientras que la Universidad Antonio Nariño, publicó 260 documentos en Scopus de los cuales el 62,31 se encuentran en revistas de primer cuartil.

A continuación se presenta un análisis del top 5 de las universidades colombianas con mayor número de publicaciones en revistas de primer cuartil (Q1). En su orden: 
Universidad Antonio Nariño, Universidad de los Andes, Universidad El Bosque, Universidad del Rosario y Universidad de Bogotá Jorge Tadeo Lozano.

\section{a. Universidad Antonio Nariño}

Teniendo en cuenta los otros indicadores del ranking SIR Iber 2.014, se observa, por ejemplo, que la Universidad Antonio Nariño (UAN) se encuentra en la posición 18 con tan solo 260 publicaciones, por debajo de la Universidad de los Andes que ocupa el primer lugar de este grupo con 2.423 artículos y la Universidad El Bosque con 190 documentos indexados en Scopus, según el criterio Output (O); mientras que en lo que respecta a la colaboración internacional, la UAN se encuentra en primer lugar con el $83,08 \%$ de sus publicaciones elaboradas conjuntamente con otros países, por encima de la Universidad de los Andes con 56,62 y la Universidad de Bogotá Jorge Tadeo Lozano. Es de anotar que este indicador es muy importante para la visibilidad de las Instituciones de Educación Superior.

La Universidad Antonio Nariño tiene 25 grupos de investigación avalados por Colciencias, 14 de los cuales están clasificados en la categoría C. La principal investigadora es Martha Losada líder de los grupos de Física-Fenomenología de Partículas Elementales y Cosmología y Experimental High Energy Physics. Consecuente con esta información, esta investigadora se perfila como la más productiva (78 firmas) en 2014, con un índice H de 44 y un promedio mensual de 6.5 investigaciones, seguida de Gabriela Alejandra Navarro con 76 documentos, un índice $\mathrm{H}$ de 40 y un promedio mensual de 6.3 investigaciones.

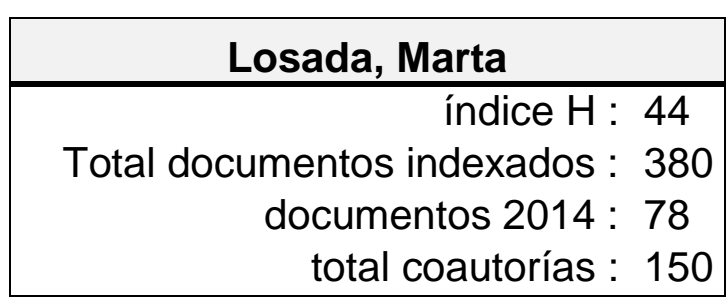

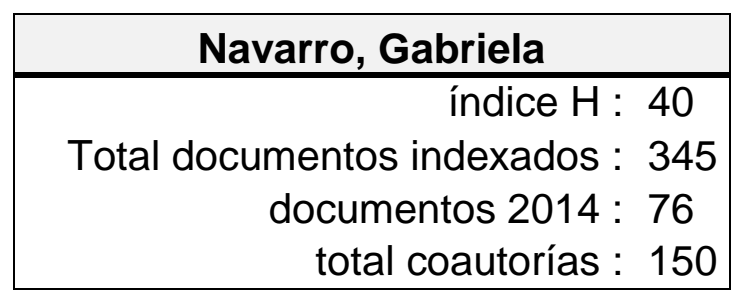

Se advierte una clara tendencia de las autoras más productivas a escribir en colaboración con otros autores e instituciones, como se observa en los cuadros 1 y 2 (porcentaje de colaboración internacional \% IC), así como en sus respectivas fichas descriptivas que muestran 150 trabajos en coautoría. 
Es prudente mencionar que Scopus visualiza únicamente 150 coautorías en el análisis de cada autor. Esta colaboración posibilita mayor visibilidad de la producción intelectual y, por consiguiente, aumenta la probabilidad de recepción de citas. Es importante aclarar que el índice de colaboración podría ser originado por la participación de las autoras en la publicación de artículos científicos producto de los experimentos desarrollados en la Organización Europea para la Investigación Nuclear (CERN) y los proyectos que allí se desarrollan, como por ejemplo el proyecto ATLAS, uno de los más importantes experimentos desarrollados en el campo de la física de partículas.

\section{Gráfico 2 \\ Principales revistas en donde publican los autores de la Universidad Antonio Nariño}

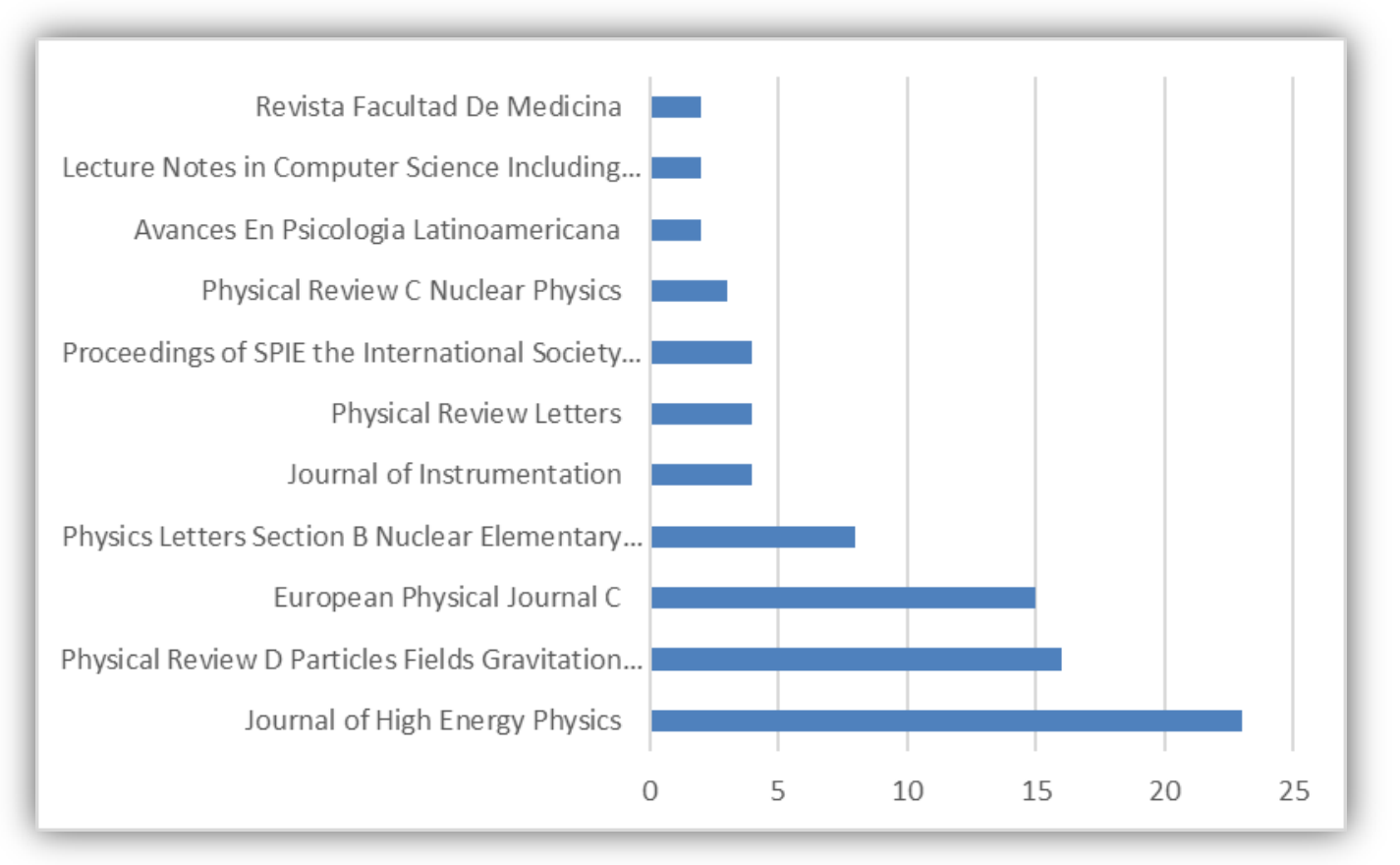

Fuente: Diseño propio basado en datos tomados de Scopus, consulta realizada Julio de 2015.

En el gráfico se observa que la mayoría de la producción científica de la universidad Antonio Nariño se publica principalmente en tres revistas de corriente principal en física: Journal of High Energy Physics clasificada en el cuartil 2 con un factor de impacto de 6,111 y un índice de inmediatez de 2,347, Physical Review publicada por la American Physical Society, desde 1999 en cuartil 1 y un índice h de 452 y la European Physical Journal que ha fluctuado entre los cuartiles 1 y 2 desde 1999. 


\section{b. Universidad de los Andes}

En la segunda posición del ranking, según el criterio Q1, referente al porcentaje de publicaciones en revistas de primer cuartil, con $(39,66)$, se encuentra la Universidad de los Andes con 654 investigaciones. En esta universidad, en el año 2014 se destacan por su producción científica los autores Carlos Arturo Ávila Bernal, cuyo índice h es de 52 y 600 artículos indexados, Juan Carlos Sanabria con índice h de 48 y 429 documentos indexados, Bernardo Gómez Moreno índice h de 45 y 366 documentos indexados y finalmente, Cesar Flórez Arboleda con índice h de 45 y 369 documentos indexados. Es de anotar que estos autores tienen el mismo número de coautorías, 150.
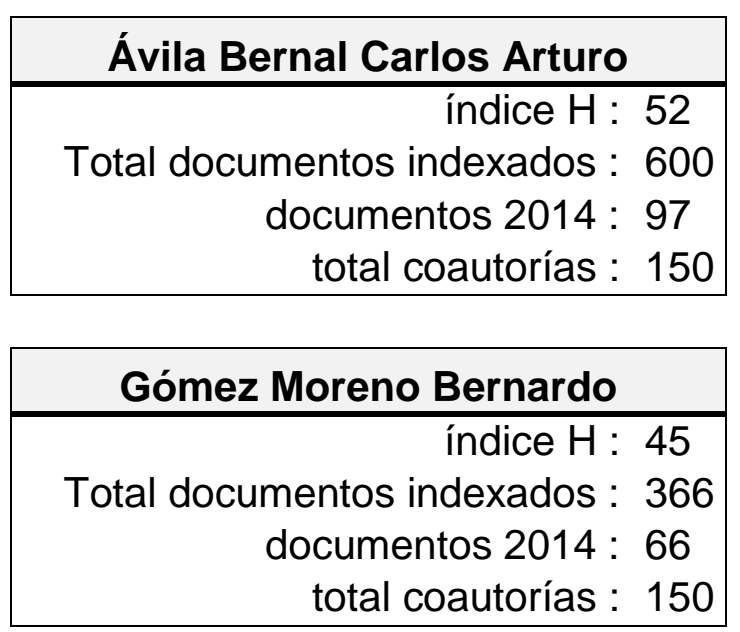
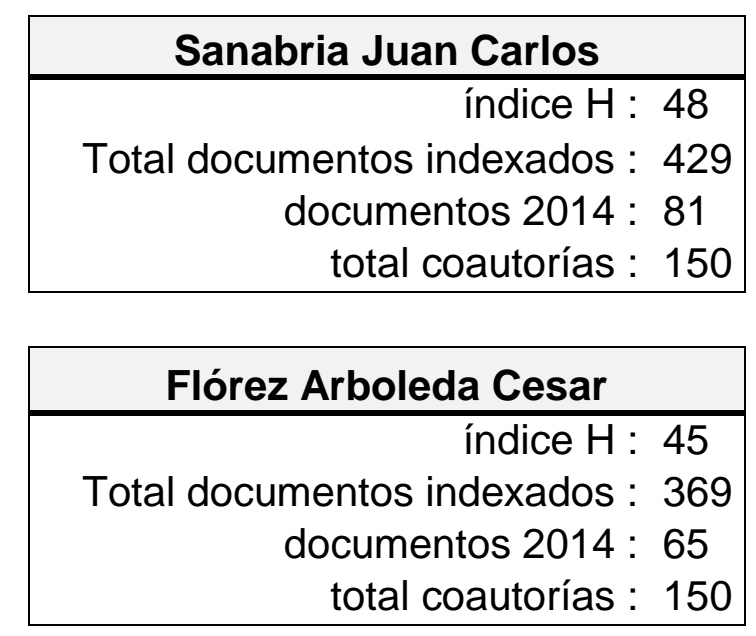

La Universidad de los Andes tiene un amplio porcentaje de grupos de investigación, la mayoría de los cuales se encuentran clasificados en las categorías $\mathrm{C}$ y A1, seguido de los que pertenecen a la categoría $\mathrm{D}$. Dichos autores tienden a publicar sus artículos en una gran variedad de revistas, siendo las más recurrentes Physical Review D Particles Fields Gravitation and Cosmology, con 24 artículos, Journal of High Energy Physics con 23, posteriormente se dispersa la publicación en otros 52 títulos. Es importante resaltar que 64 revistas del total son de primer cuartil y 65 de segundo. La distribución por áreas del conocimiento de la Universidad de los Andes, dominada por física y astronomía (25.5\%), seguida de ciencias sociales e ingeniería, se evidencia en el siguiente gráfico. 


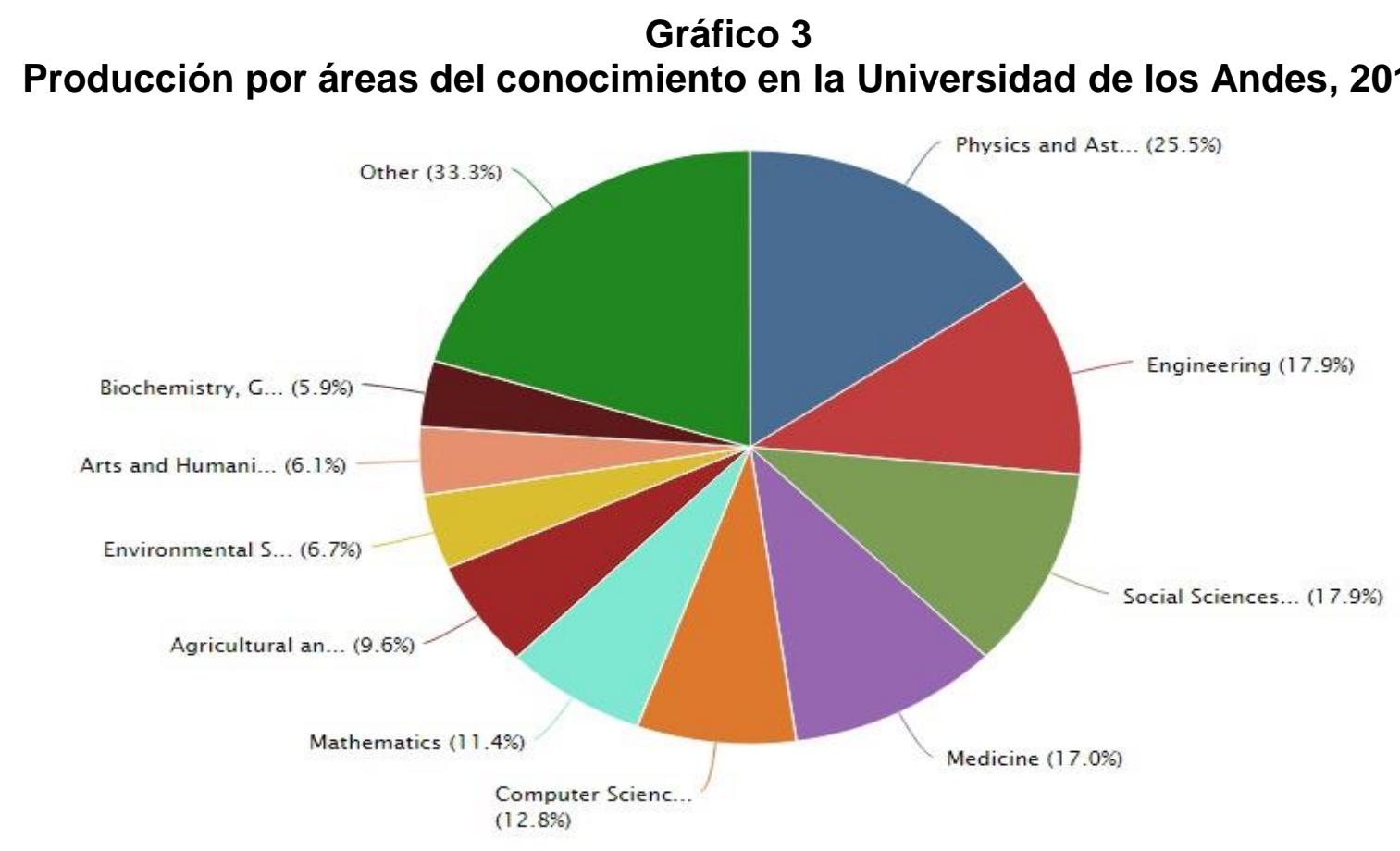

Fuente: Scopus. Consulta realizada en Julio de 2015.

La colaboración interinstitucional de la Universidad de los Andes se centra en trabajos realizados principalmente con el "Fermi National Accelerator Laboratory" de la Organización Europea para la Investigación Nuclear (CERN), que contribuye a que esta Institución de Educación Superior alcance un importante porcentaje en el criterio de liderazgo científico 51.22, reafirmando así el amplio reconocimiento de que goza como institución líder en investigación y publicación de trabajos en revistas de alto impacto.

\section{c. Universidad de El Bosque}

El tercer lugar del escalafón es para la Universidad El Bosque, institución que a pesar de tener un importante porcentaje de artículos publicados en revistas de primer cuartil $(38,95)$ se ubica en el puesto 23 según el criterio Output "O" con 190 artículos indexados en Scopus. Esta universidad publicó 81 documentos en el año 2014, lo cual permite inferir que, si bien es cierto, es una de las universidades que está en los cinco primeros lugares según el criterio \%Q1 que analiza el porcentaje de publicaciones en revistas de primer cuartil, al realizar el análisis con otros criterios del ranking SIR Iber 2014, la situación varía. 
La Universidad El Bosque tiene 28 grupos de investigación avalados por Colciencias, la mayoría de los cuales se encuentran en las categorías C y B. Solo el grupo liderado por Jaime Eduardo Castellanos Parra, el autor más prolífico de la universidad, pertenece a la categoría A1. La universidad tiene 316 autores entre quienes se encuentran Jaime Eduardo Castellanos Parra con 7 documentos y Lorena Díaz con 5 documentos del 2014, seguidos por Jinnethe Cristina Reyes Manrique y Sandra Rincón con 4 investigaciones cada una, según se observa en las siguientes fichas descriptivas:
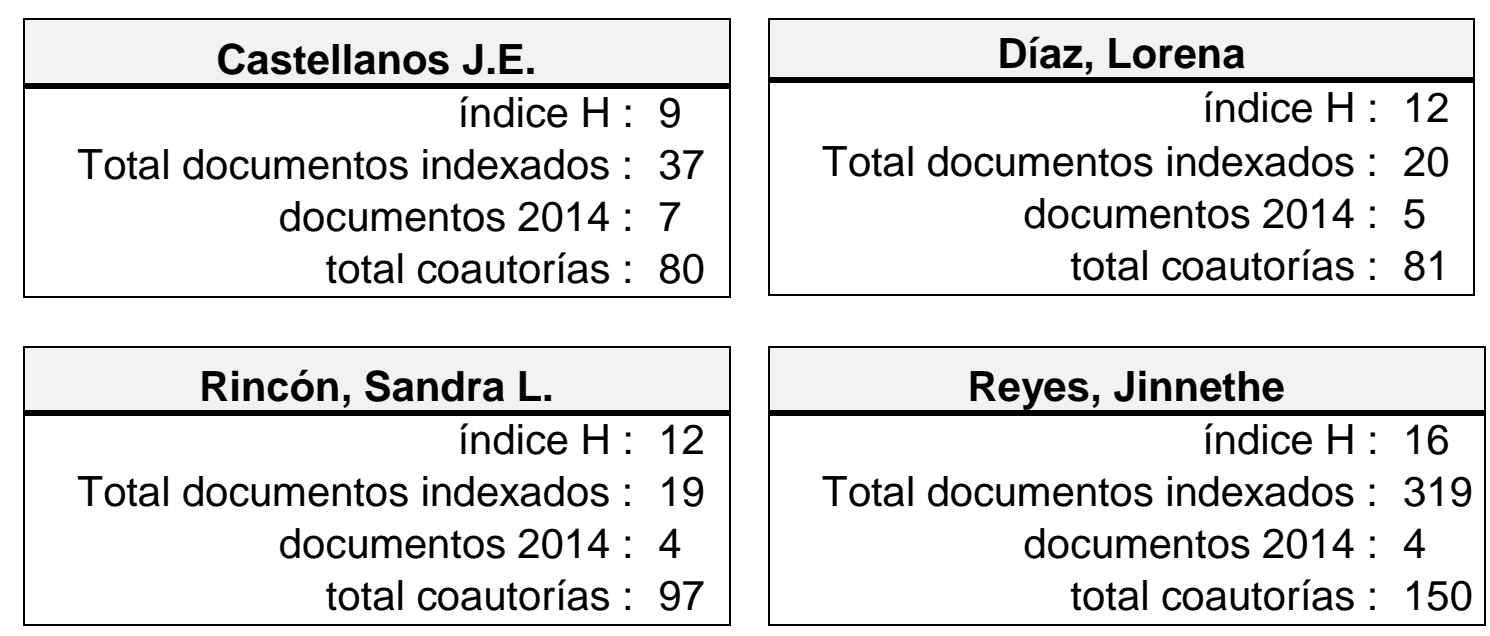

En el Gráfico 4 se observan las principales revistas en las que publican los dos autores más productivos de esta universidad. Un porcentaje significativo de investigadores publican en revistas de primer (41\%) y segundo cuartil (11\%). En lo relacionado con el indicador de colaboración interinstitucional, la mayoría de trabajos se realizan con universidades nacionales (72 artículos), mientras que en el ámbito internacional el porcentaje de trabajos publicados es bajo (21 artículos), evidenciándose un bajo rendimiento en el criterio Liderazgo científico "\%Lead" $(32,63)$. 


\section{Gráfico 4 \\ Principales Revistas en donde publican los 2 principales autores de la Universidad del Bosque en 2014}

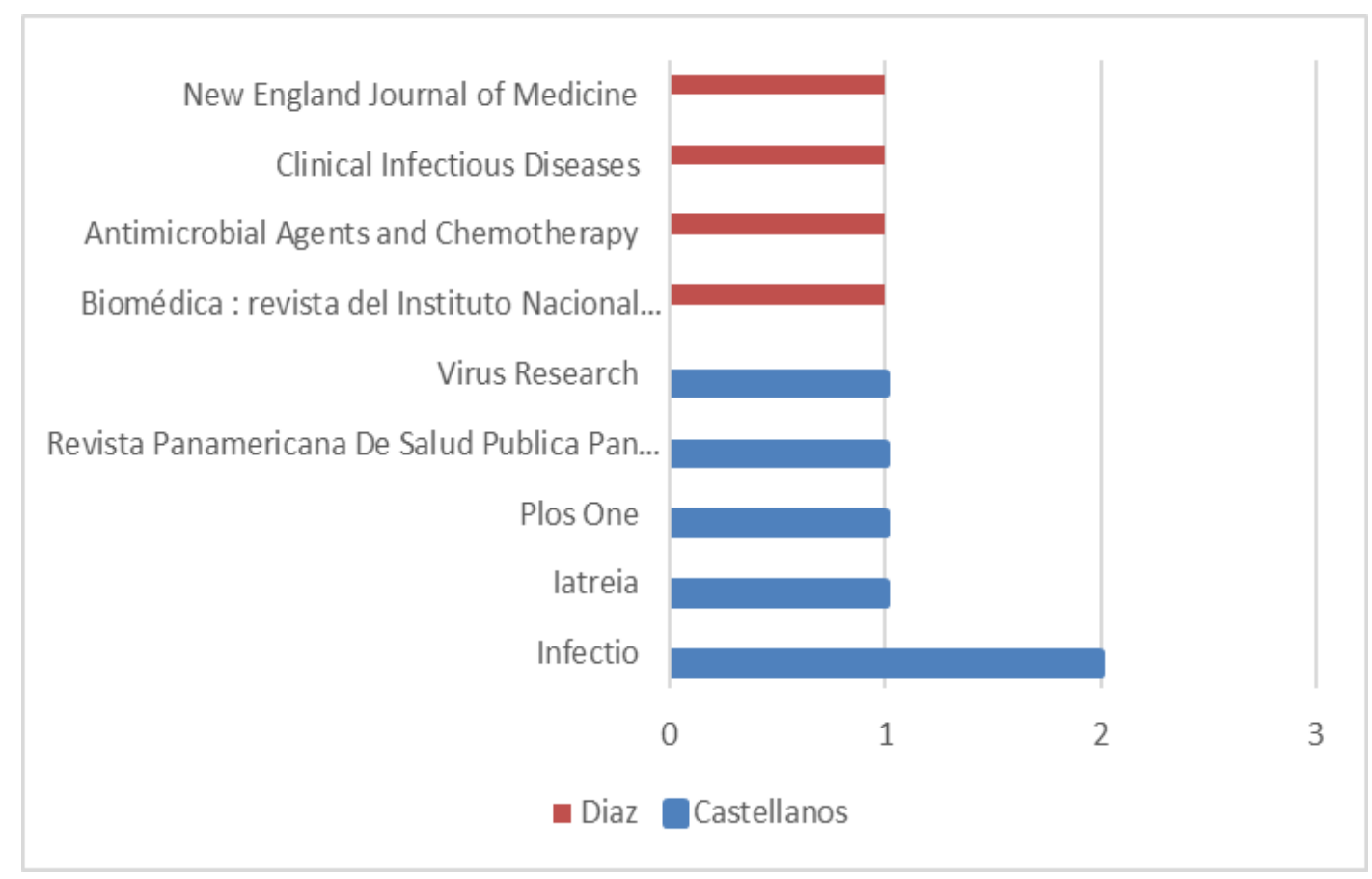

Fuente: Scopus. Consulta realizada el 25 de Julio de 2015.

\section{d. Universidad del Rosario}

La Universidad del Rosario con un porcentaje de revistas de primer cuartil (\%Q1), correspondiente a 30,24 y 711 artículos publicados en Scopus (Output O), se posiciona en el cuarto lugar del ranking SIR Iber 2014.

En el 2014 la Universidad del Rosario tenía 8 grupos de investigación en la categoría principal según Colciencias, como se observa en el Gráfico 5, entre los que se encuentran el Centro de Estudios de Enfermedades Autoinmunes CREA, grupo de Genética Evolutiva, Filogeografía y Ecología de Biodiversidad Neotropical, entre otros. Los grupos de investigación son clasificados por Colciencias en las categorías: grupos registrados, reconocidos y medidos. Los grupos reconocidos se miden y diferencian por medio de la identificación en cuatro categorías ( $\mathrm{A} 1, \mathrm{~A}, \mathrm{~B}$ y $\mathrm{C}$ ), de las cuales la categoría $\mathrm{A} 1$, es la de máximo nivel. Esta clasificación depende de los productos o resultados de investigación que generen nuevo conocimiento: artículos, capítulos, libros de investigación; productos o 
procesos tecnológicos patentados o registrados, como también los usualmente no patentables o protegidos por secreto industrial; normas basadas en resultados de investigación, literatura gris y otros productos no certificados. Cada uno de los productos tiene diferente puntuación, con un peso relativo de indicador que oscila entre cero y uno.

Las revistas en las cuales los autores de la Universidad del Rosario publicaron la mayor cantidad de artículos son Plos One, Peace Economics Peace Science and Public Policy, Social Choice and Welfare, con 9, 5 y 4 publicaciones en cada revista respectivamente.

\section{Gráfico 5}

Grupos de investigación de la Universidad del Rosario, 2014

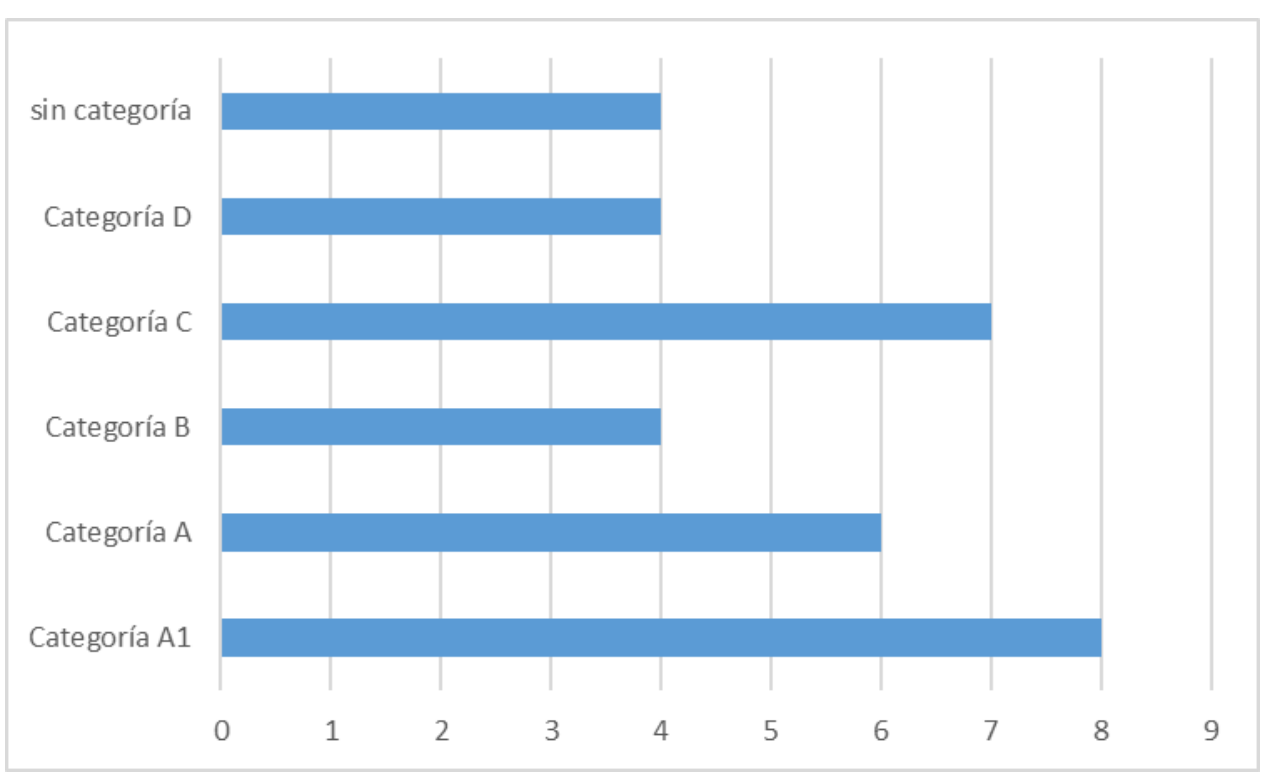

Diseño propio con datos tomados de Colciencias. Consultado en julio de 2015.

Entre los autores más productivos de la Universidad del Rosario se encuentran los doctores Juan Manuel Anaya, líder del grupo del Centro de Estudios de Enfermedades Autoinmunes CREA y Manuel Alfonso Patarroyo Gutiérrez, miembro del grupo de Investigaciones Microbiológicas, de quienes se observa su ficha descriptiva. 

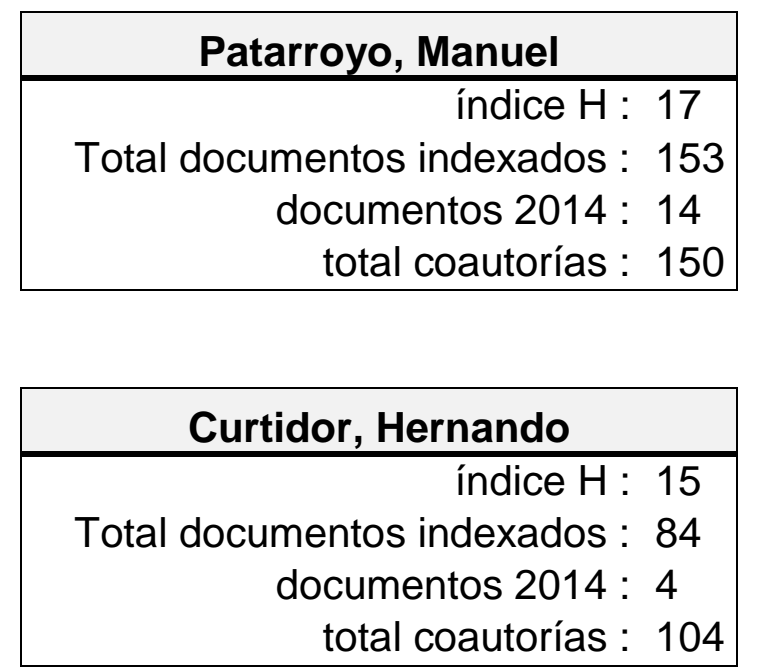

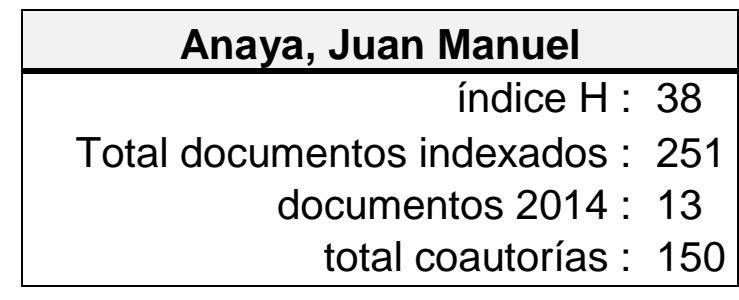

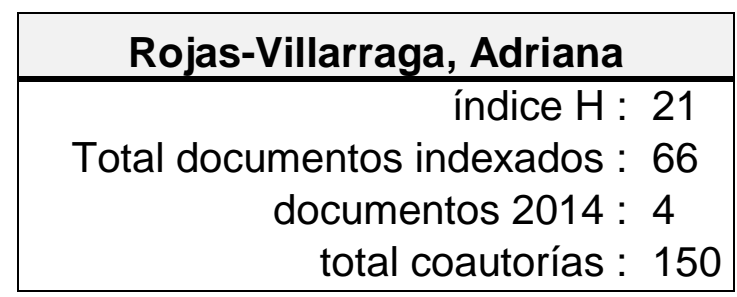

En el siguiente mapa se muestra la tendencia del trabajo colaborativo que la Universidad del Rosario realiza con otros países.

\section{Figura 2}

Mapa de Colaboración internacional de la Universidad del Rosario

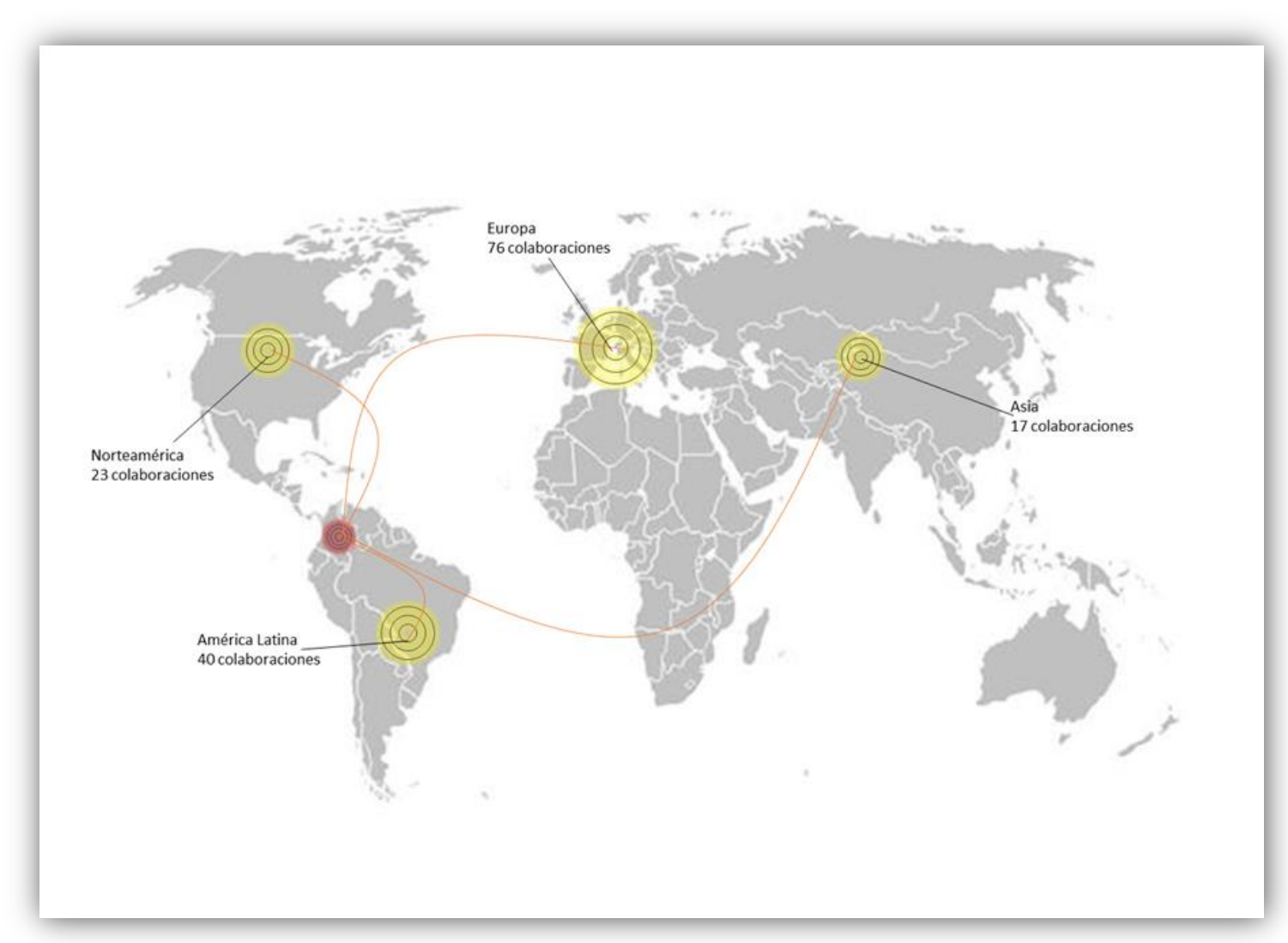


Diseño propio con datos tomados de Scopus. Consultado en julio de 2015

El trabajo que realiza la Universidad del Rosario con organismos de diferentes países como Harvard Affiliated Emergency Medicine Residency, Georgia Regents University, Harvard Medical School, Yale University, entre otras, ha llevado a que obtenga importantes reconocimientos en investigación. El puntaje según el liderazgo científico es de 51,76.

\section{e. Universidad Jorge Tadeo Lozano}

Ubicada en el quinto lugar del ranking SIR Iber 2014, según el criterio de análisis y con un puntaje de 28,97 de \%Q1, esta universidad ocupa la posición 29, de acuerdo con el criterio Output con 145 investigaciones publicadas. Tiene 33 grupos de investigación, de los cuales el grupo de Modelado y Simulación de Sistemas se encuentra clasificado en la Categoría A1.

\section{Gráfico 7}

Principales revistas en donde publican los autores de la Universidad Jorge Tadeo Lozano en 2014

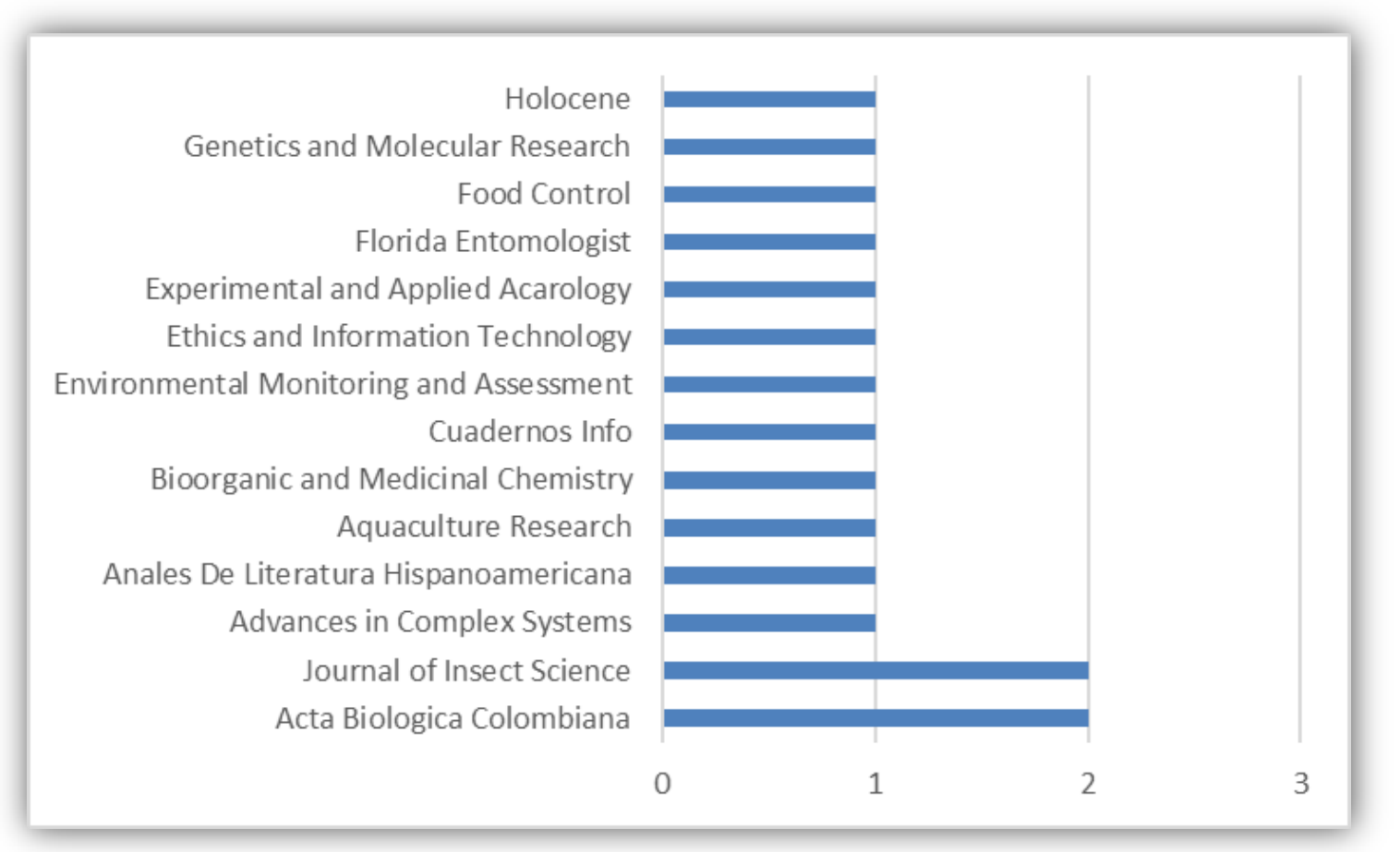

Fuente: Scopus. Consulta realizada en Julio de 2015. 
Sus principales investigadores Carlos Ricardo Bojacá Aldana y Javier Adolfo Hernández Fernández publicaron 2 investigaciones cada uno en el año 2014, en las revistas Food Control, Journal of Cleaner Production, Genetics and Molecular Research y Revista Brasileira De Fruticultura, respectivamente. Entre las revistas de primer cuartil en las que publicaron investigadores de la Universidad Jorge Tadeo Lozano se encuentran el Journal of Cleaner Production, Food Control, Weed Research y Journal of Cleaner Production, con un artículo en cada una. Este análisis permite inferir que la actividad investigativa en la Universidad Jorge Tadeo Lozano apenas está emergiendo; sin embargo, es necesario destacar que ha desarrollado investigaciones importantes publicadas en revistas de alto impacto, pertenecientes al primer cuartil.

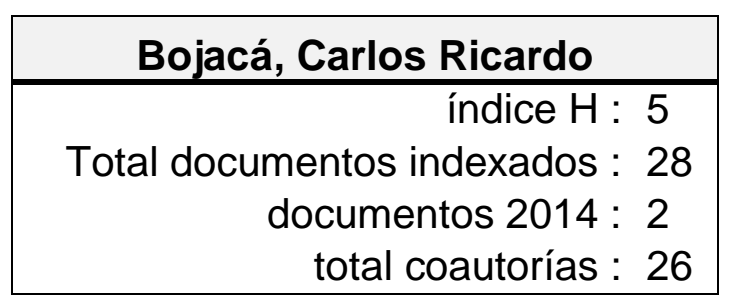

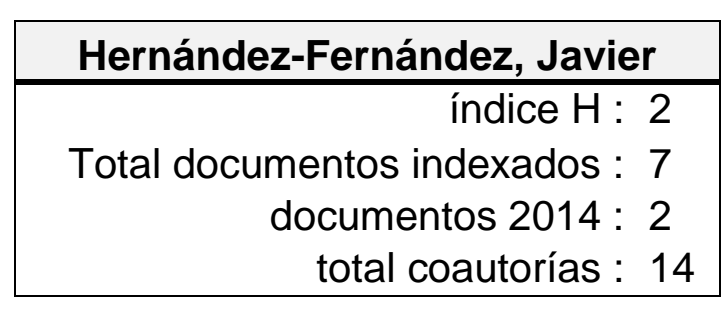

El análisis por áreas del conocimiento muestra que los principales trabajos en esta universidad se han efectuado en áreas como agricultura (30,8\%), arte $(12,8 \%)$, ciencias medioambientales $(12,8 \%)$ y bioquímica $(10,3 \%)$, respectivamente.

La tendencia a realizar trabajos colaborativos con instituciones nacionales es baja (8 investigaciones conjuntas con la Universidad Nacional de Colombia) en comparación con otras universidades de Colombia. En el ámbito internacional esta universidad realiza investigación con instituciones de Bélgica, Alemania, Holanda España y Estados Unidos (2 investigaciones por país), entre las que se encuentran la Vietnamese Academy of Agricultural Science, University of Manchester y University of Florida, entre otras. La Universidad obtuvo una puntuación de 55,17 en liderazgo científico a pesar de tener una cantidad baja de publicaciones indexadas y no participar en grandes redes de cooperación, pero con publicación de trabajos en revistas de alta calidad. 


\section{Conclusiones}

Los rankings son una realidad a la cual las instituciones de educación superior no se pueden sustraer, pues al hacerlo estarían desconociendo su importancia y la posibilidad de incidir en la educación superior. No obstante, su uso debe ser visto con precaución teniendo en cuenta el contexto en el cual surgen y su papel en contraposición con otros mecanismos más orientados al aseguramiento de la calidad, aun cuando pueden ser considerados como fuente de información y de referencia. Se comprueba la dificultad que plantea Chubb (2007) para comparar diferentes instituciones de educación superior con diferentes propósitos y objetivos institucionales que operan además en diferentes entornos socio-económicos y culturales.

Los rankings consideran en sus mediciones aspectos de la reputación de las IES, que privilegian la trayectoria sobre la capacidad innovadora actual, lo cual hace que hechos del pasado de instituciones de larga trayectoria y de reconocimiento social tengan mayor peso en algunos rankings, en detrimento de los esfuerzos de nuevas instituciones.

La medición de las universidades a través de criterios bibliométricos permite aplicar métodos objetivos y matemáticos para posicionar las IES de acuerdo con los criterios preestablecidos, pero teniendo en cuenta que los indicadores bibliométricos siempre son relativos (González de Dios, Moya y Mateos, 1997). Aunque se nota un avance en este sentido, lo cierto es que el peso específico de la publicación de trabajos de las universidades colombianas como un indicador de medición de impacto y visibilidad de las mismas, todavía es bastante escaso.

Es necesario tomar distancia de los rankings universitarios que son aceptados como paradigmas de la calidad de las IES; no obstante, sus limitaciones frente a la incapacidad para poder capturar a través de una medición única la gran riqueza y variedad de estas instituciones (Pérez Alemán, 2016). Colombia aumentó el número de instituciones con presencia en la base de datos Scopus y en los rankings internacionales, principalmente a partir del 2013 (Scimago Research Group, 2014). 
La participación de las universidades colombianas en convenios de colaboración científica internacionales e interinstitucionales, como el realizado por varias universidades con el CERN, aumentan considerablemente el posicionamiento y visibilidad de las universidades en los rankings internacionales. Sin embargo, requieren de un cuidadoso análisis por cuanto podrían desvirtuar los resultados de la productividad tanto de los autores como de las instituciones en períodos de análisis relativamente cortos. En este orden de ideas, el hecho de que los autores aparezcan como firmantes de los trabajos colaborativos (para el caso del CERN) beneficia a los autores, pero muestra una producción de alguna manera irreal.

Publicar sus investigaciones en revistas de primer cuartil exige grandes retos a las universidades colombianas. Participar en redes de cooperación, como las desarrolladas en el CERN, permite a las IES la posibilidad de mejorar su puntuación en el criterio "\%Q1"; sin embargo, no se evidencia participación en dichas investigaciones (Creus y Canals, 2014), como es el caso de la Universidad Antonio Nariño y Andes. Un porcentaje importante de sus publicaciones de primer cuartil depende de estas publicaciones en colaboración; no en vano se ubicaron en las dos primeras posiciones en el ranking, según el criterio "\%Q1". En contraparte, las universidades El Bosque, Rosario y Jorge Tadeo Lozano, que a pesar de no pertenecer a grandes grupos de investigación, publicaron un porcentaje significativo de sus investigaciones en revistas de alta calidad.

La relación entre la cantidad de las investigaciones, el porcentaje de publicaciones de alta calidad y el liderazgo de cada universidad se evidencia en el criterio "\%Ewl", excelencia con liderazgo. La clasificación de las cinco universidades analizadas, según este criterio, presenta el siguiente orden: en primer lugar la Universidad El Bosque, cuyo puntaje es de 2,66; seguida de la Jorge Tadeo Lozano (2,22), Los Andes $(2,2)$, la Universidad del Rosario $(1,87)$ y, finalmente, la Universidad Antonio Nariño $(0,8)$. De esta observación se infiere que no es necesario liderar las investigaciones para lograr posiciones privilegiadas en los rankings y reconocimiento como instituciones productoras de investigaciones de alta calidad. 
Otra situación presenta la Universidad Nacional que es la universidad con mayor cantidad de publicaciones, de acuerdo con el ranking SIR Iber 2014, con 6.077 publicaciones indexadas, pero que no logró acceder a las cinco primeras posiciones, según el criterio "\%Q1" en el que obtuvo una puntuación de 21,24 ubicándose por debajo de instituciones con un número mucho menor de investigaciones publicadas; este hecho evidencia que a mayor cantidad de investigaciones publicadas, más complicado es lograr que un porcentaje amplio de estas sea publicado en revistas de alta calidad.

Los programas formalizados de investigación proporcionan a las universidades colombianas la posibilidad de publicar los resultados de las investigaciones en revistas indexadas, lo que mejora la visibilidad y, por ende, el posicionamiento en los distintos rankings.

La participación en los convenios internacionales e interinstitucionales de investigación, como los desarrollados en la Organización Europea para la Investigación Nuclear (CERN), aumentan considerablemente el posicionamiento de las universidades en los rankings internacionales.

El análisis de las áreas temáticas del conocimiento permite identificar los frentes de investigación activos o especialidades en las universidades analizadas. Los autores más prolíficos, que generalmente trabajan en la misma especialidad y forman parte de los grupos de investigación, conforman los ya conocidos colegios invisibles.

No se puede asumir que todo el conocimiento obtenido por los científicos de las universidades estudiadas se encuentra en los trabajos publicados en revistas de primer cuartil, como tampoco que el cómputo de las publicaciones proporciona una clara idea de la calidad de las mismas.

Las exigencias de las instituciones de educación superior (IES) a sus investigadores para publicar mayor número de resultados de investigación en revistas de primer cuartil, llevan a que el conocimiento se fraccione en el intento de publicar varios trabajos en lugar de uno para ganar currículo. 
Los criterios de los rankings para analizar la producción de las universidades a través de la publicación de los productos de investigación en revistas de primer cuartil, no tiene en cuenta la producción publicada en revistas no indexadas y en las altmetrics.

El criterio \%Q1, del ranking SIR Iber 2014, castiga a aquellas universidades que tienen una tradición investigativa importante, pero no logran publicar en revistas de primer cuartil. Un claro ejemplo de lo anterior es la Universidad Nacional de Colombia, no incluida en este análisis, la cual a pesar de haber publicado 6.077 artículos en el 2014, aparece con apenas un $21,24 \%$ en revistas de primer cuartil, siendo superada en este criterio por instituciones con una cantidad de artículos mucho menor, pero publicados en revistas de este cuartil.

\section{Referencias}

Arencibia-Jorge, R., Vega-Almeida, R. L., Chinchilla-Rodríguez, Z., Corera-Álvarez, E. y Moya-Anegón, F. (2012). Patrones de especialización de la investigación nacional sobre Salud. Revista Cubana de Salud Pública, 38 http://dx.doi.org/10.1590/S0864-34662012000500007

Chubb, I. (2007). Distinguishing (Between) Universities. En: Sadlak J. y Nian, L. (eds.) The World-Class University and Ranking: Aiming Beyond Status. Bucarest: UNESCO-CEPES.

Creus, A. (2014). Desarrollo profesional e intercambio de conocimiento en los grandes experimentos científicos. Revista Española de Documentación Científica, 37 (4).

Gonzáles de Dios, J.; Moya, M. y Mateos-Hernández, M. (1997). Indicadores bibliométricos: características y limitaciones en el análisis de la actividad científica. Anales Españoles de Pediatría, Vol. 47 (3)

Knowledge. BiblioSaúde. Recuperado de http://bibliosaude.sergas.es/DXerais/481/COMO\%20CALCULAR\%20EL\%20CUARTI L\%20DE\%20UNA\%20REVISTA\%20CIENT\%C3\%8DFICA.\%20isi\%20wEB\%20OF\% 20kNOWLEDGE.pdf

López, E. (2012). Cómo se cocinan los rankings universitarios. Dendra Médica. Revista de Humanidades, 11 (1). 
López, O. y Cordero, A. (2015). Un intento por definir las características generales de las revistas académicas electrónicas. Razón y Palabra. Recuperado de http/www.cem.itesm.mx/publicaciones/logos/libros/index.html

Lopez-Illescas, C., de Moya-Anegón, F. y Moed, H.F. (2011). A ranking of universities should account for differences in their disciplinary specialization. Scientometrics, 88 (2). http://dx.doi.org/10.1007/s11192-011-0398-6

López L., S. (2012). Los rankings universitarios. Bases teóricas, metodología y su impacto en la educación superior global. Revista de la educación superior, 51 (161).

Mattar V, González T, M. y Salgado A, L., (2013). Análisis de las universidades colombianas de acuerdo con el ranking SCImago 2010-2012. En MVZ Córdoba 18 (1).

Moed, H.F., Moya-Anegón, F., López-Illescas, C., Visser, M. (2011). Is concentration of university research associated with better research performance? Journal of Informetrics, 5 (4). http://dx.doi.org/10.1016/j.joi.2011.06.003

Molina-Molina, S. y De Moya-Anegón, F. (2013). Política nacional y visibilidad internacional. El caso colombiano. El Profesional de la Información, 22 (6).

Nian, L., Y. C. (2007). Academic Ranking of World Universities: Methodologies and Problems. En: Sadlak J. y Nian, L. (eds.). The World-Class University and Ranking: Aiming Beyond Status. Bucarest: UNESCO-CEPES.

Pérez, Y. (2016). Los rankings y la calidad de la educación superior. Recuperado de http://www.universidad.edu.co/index.php?option=com_content\&view=article\&id=674 7:2016-04-03-17-59-03\&catid=36:ensayos-acadcos\&ltemid $=81$

Pinski, G. and Narin, R. (1996). Citation influence for journal aggregates of scientific publications: theory with application to the literatura of physics. Information Processing and management. No. 12. Recuperado de http://sci2s.ugr.es/sites/default/files/files/TematicWebSites/hindex/PinskiNarin1976.p df

Plata, J. (2013). Las universidades y la planificación de la investigación y la innovación. Los retos éticos en el nuevo siglo. Memorias. XII Congreso "La Investigación en la Pontificia Universidad Javeriana". Tercera sesión del simposio sobre fortalezas de investigación, un conversatorio sobre experiencias nacionales en la definición de agendas de investigación. 
Bibliotecas. Vol 35, N³, julio-diciembre, 2017. EISSN: 1659-3286

URL: http://www.revistas.una.ac.cr/index.php/bibliotecas/index

Principales revistas en donde publican los autores de la Universidad Jorge Tadeo Lozano (2014). Recuperado de Scopus. [Disponible en https://www.scopus.com/search/form.uri?display=basic]

Producción por áreas del conocimiento. Universidad de los andes (2014). Recuperado de Scopus. [Disponible enhttps://www.scopus.com/search/form.uri?display=basic]

Sadlak, J. (2004). Ranking and League Tables of Universities and Higher Education Institutions - Methodologies and Approaches - Collection of Texts. Washington: UNESCO-CEPES.

Sadlak, J. y Nian, L. (eds.) (2007). The World-Class University and Ranking: Aiming Beyond Status. Berlin Principles on Ranking of Higher Education Institutions. Bucarest: UNESCO-CEPES, p. 25-28.

Sapiens Research Group (2014). Indicadores del ranking U-Sapiens. Recuperado de http://www.sapiensresearch.org/usapiens/2015-1/metodologia.html

Scimago Lab (2011). Informe Mundial SIR 2011 sobre investigación. Recuperado de http://www.scimagolab.com/

Scimago Research Group (2014). SIR lber 2014. Recuperado de http://www.scimagoir.com/pdf/iber_new/SIR\%20lber\%202014\%20HE.pdf

Shin, J. (2011). Organizational Effectiveness and University Rankings. En: Shin, J., Toutkoushian, R. y Teichler, U. (eds.). University Rankings. Theoretical Basis, Methodology and Impacts on Global Higher Education. Dordrecht: Springer.

Sobrido M. (2011). Como calcular el cuartil de una revista científica en ISI Web Of

Knowledge. BiblioSaúde. Recuperado de

http://bibliosaude.sergas.es/DXerais/481/COMO\%20CALCULAR\%20EL\%20CUARTIL\%20D E\%20UNA\%20REVISTA\%20CIENT\%C3\%8DFICA.\%20isi\%20wEB\%20OF\%20kNOWLEDG E.pdf

\section{Notas sobre los autores}

* Rosa Elena Gómez Hurtado: Bibliotecóloga, Magister en Administración de Empresas, Magistra en Relaciones Internacionales. Docente investigadora - Ciencia de la Información y Bibliotecología. Fundación Universitaria UNINPAHU.Calle 83ª No. 116ª̣-85 Bogotá, D.C. Colombia. Correo electrónico rosikigomez@gmail.com 
** Alexander Gerena Herrera: Bibliotecólogo, egresado de la Fundación Universitaria UNINPAHU. Carrera 88d 8å-81 interior 140 Bogotá D. C. Colombia. Correo electrónico axlger@gmail.com

\section{Agradecimientos}

Los autores expresan su agradecimiento a David Barrera y Edwin Camacho por su colaboración en la investigación, al igual que a la Fundación Universitaria UNINPAHU por el apoyo.

Acknowledgements: The authors would like to thank David Barrera and Edwin Camacho for their collaboration in research, like the Fundación Universitaria UNINPAHU for the support during this research. 